\title{
The effect of coping strategy on quality of life in patients with NSCLC
}

This article was published in the following Dove Press journal: Cancer Management and Research

\author{
Mariusz Chabowski ${ }^{1,2}$ \\ Beata Jankowska-Polańska ${ }^{3}$ \\ Katarzyna Lomper ${ }^{3}$ \\ Dariusz Janczak ${ }^{1,2}$ \\ 'Division of Surgical Procedures, \\ Department of Clinical Nursing, \\ Faculty of Health Science, Wroclaw \\ Medical University, Wroclaw, Poland; \\ ${ }^{2}$ Department of Surgery, 4th Military \\ Teaching Hospital, Wroclaw, Poland; \\ ${ }^{3}$ Division of Nursing in Internal \\ Diseases, Department of Clinical \\ Nursing, Faculty of Health Science, \\ Wroclaw Medical University, Wroclaw, \\ Poland
}

Background: A cancer diagnosis is a source of emotional distress. The aim of the study was to evaluate coping strategies in patients with non-small-cell lung carcinoma and to assess how coping strategies along with other factors affect their quality of life.

Patients and methods: A total of 185 patients with non-small-cell lung carcinoma were enrolled in this observational, cross-sectional study. Demographic and clinical data were collected. Strategies for coping with cancer were assessed using a shortened version of the Mental Adjustment to Cancer (MiniMAC) scale. Health-related quality of life was assessed using the Short Form-8 Health Survey.

Results: Respondents (mean age: $62.84 \pm 9.6$ years) most often emerged as using a fighting strategy, whereas a sense of helplessness was the strategy used least often. Overall, $65 \%$ of the respondents were revealed to have a medium level of constructive style of coping, whereas $62 \%$ had a medium level of destructive style. The coping style of nearly $50 \%$ of the respondents was predominantly constructive. Patients whose coping style was predominantly constructive had a significantly higher level of quality of life than patients whose coping style was predominantly destructive or whose results showed a balance between the two coping styles. Lung cancer patients had higher scores on the mental functioning scale (mental component summary $=50.20 \pm 39.26$ ) than on the physical functioning scale (physical component summary $=40.07 \pm 28.58$ ).

Conclusion: The majority of lung cancer patients use effective strategies for coping with the disease, which correlates with a better quality of life; a compromised quality of life is associated with a destructive coping style. Physicians should endeavor to promote positive, constructive, problem-oriented strategies of coping, especially in patients with a compromised quality of life, where the disease is advanced and when there are comorbidities.

Keywords: lung cancer, coping strategy, quality of life

\section{Introduction}

Cancer patients experience reduced quality of life in comparison with healthy subjects as the diagnosis of cancer brings acute emotional distress. This diagnosis followed by treatment, which may include extensive surgery, toxic chemotherapy, and radiation therapy, affects patients' behavior and may have an impact on patient motivation to continue treatment and to cope with their disease. Patients' reactions to such stressors depend on many factors; thus, the ability to battle with cancer, side effects of the treatment, possible complications, and cancer rehabilitation varies among patients. Many tools are used to attempt to evaluate coping with chronic diseases; however, cancer patients require a special approach. ${ }^{1,2}$
Correspondence: Mariusz Chabowsk Department of Surgery, 4th Military Teaching Hospital, 5 Weigla Street, 50-98I Wroclaw, Poland

Tel +48261660247

Fax +48261660245

Email mariusz.chabowski@gmail.com 
The way people react to serious stressors plays a significant role in their quality of life. In cancer patients, adaptation to changes made by the diagnosis of cancer depends on the coping strategy they employ. Dunkel-Schetter et $\mathrm{al}^{3}$ determined five patterns of coping in cancer patients, namely, seeking and using social support; focusing on the positive; distancing; cognitive escape avoidance; and behavioral escape avoidance. Watson et $\mathrm{al}^{4}$ developed the Mental Adjustment to Cancer (MAC) that distinguished four styles of coping with neoplastic diseases, which are anxious preoccupation, fighting spirit, helplessness-hopelessness, and positive redefinition. Researchers found that coping based on avoidance strategies is associated with greater distress, poor outcomes, and reduced quality of life, whereas coping based on seeking support and focusing on the positive is associated with less pain and distress and fewer comorbid health conditions. ${ }^{3}$

Researchers report that coping strategies evolve over the lifetime. ${ }^{5}$ They also differ among individuals and depend on factors such as age, sex, and socioeconomic status among others. ${ }^{5}$ The socioeconomic status of lung cancer patients is particularly poor, and additionally, many of them lose the ability to work due to the severity of their disease. ${ }^{6}$ A lower level of quality of life in lung cancer patients is often associated with severe symptoms of lung cancer such as fatigue, dyspnea, and poor physical functioning (PF). ${ }^{5-8}$

The number of cancer patients is increasing, but the reduction in mortality due to cancer is still insufficient despite high expenditure on research on new cancer therapies. ${ }^{7,9}$ We believe that shedding more light on the relationship between coping strategies and quality of life will contribute to improvements in the heath of patients with neoplastic diseases. In the current literature, coping styles in cancer patients have not been studied sufficiently, especially among those with lung cancer who may have different coping strategies due to specific stressors (eg, dyspnea) and the stigma associated with smoked tobacco. The aim of this study was to evaluate coping strategies in patients with lung cancer and to assess how coping strategies along with other factors affect their quality of life.

\section{Patients and methods}

This observation-based cross-sectional study group included 185 patients with non-small-cell lung carcinoma (NSCLC), all of whom were treated in the Department of Internal Medicine at the Lower Silesian Center for Pulmonary Diseases in Wroclaw, Poland. All the patients were informed about the aim of the study; they gave their written informed consent to participate in the study and to answer the questionnaires. The data were collected 4-6 weeks since the completion of the treatment. The study was approved by the bioethics committee of the Military Medical Chamber in Warsaw (No 152/17). The STROBE guidelines were followed.

A shortened version of the MAC scale was used to evaluate strategies for coping with the disease. The scale was initially developed by Watson et $\mathrm{al}^{4}$ in 1988 as a self-rating scale to evaluate psychological adjustment to neoplastic diseases in various types and stages of cancers. It comprised 40 questions, but it was found to have low reliability in one of the strategies (denial); therefore, the new shortened version was developed. ${ }^{10}$ The shortened version of the MAC (MiniMAC) scale includes 29 Likert-type items rated on a 4-point scale that evaluates the following four types of strategies for coping with cancer:

1. Anxious preoccupation translates into anxiety that patients are not able to control. The diagnosis itself as well as the deterioration in health status reflects the level of anxiety.

2. Fighting spirit drives positive activities leading to regaining a good state of health. This strategy motivates patients to perceive the disease as a challenge.

3. Helplessness-hopelessness translates into a perceived sense of helplessness, being lost, and giving into the disease. It is associated with a withdrawal from social and professional life.

4. Positive redefinition allows patients to re-evaluate their current health problems, find hope, and enjoy their life despite being aware of suffering from a serious disease.

Each domain is scored separately with the total score from 7 to 28 . Higher scores represent a stronger identification with a given strategy. Additionally, the presence of correlation patterns among MiniMAC domains allows the identification of the following two styles of coping with a disease:

1. constructive (fighting spirit and positive redefinition) and

2. destructive (helplessness-hopelessness and anxious preoccupation).

In this study, the Polish version of the MiniMAC questionnaire was used. ${ }^{11,12}$ The reliability of the MiniMAC in Polish cancer patients is high. In the Polish population of cancer patients, the standardized Cronbach's $\alpha$ coefficients for the four domains are $0.88,0.90,0.92$, and 0.87 , respectively. ${ }^{11}$

Health-related quality of life was assessed using the Short Form-8 (SF-8) Health Survey. It is the most recent version of the health survey. This scale consists of eight subscales, 
each with an ordinal response format, and it generates two summary measures: a physical component summary (PCS) and a mental component summary (MCS). The subscales of SF-8 are as follows: PF, role limitations due to physical health problems (RP), bodily pain (BP), general health perceptions $(\mathrm{GH})$, vitality (VT), social functioning (SF), role limitations due to emotional problems (RE), and mental health (MH). Each domain is scored from 0 to 100 . Higher scores of PCS and MCS indicate a better quality of life as do all the items in the SF-8. A score of 50 is the average score in the general US population. ${ }^{13}$ In a Spanish population-based study, the SF-8 displayed very good reliability, with the Cronbach's $\alpha$ coefficient of 0.92 and high item-total correlations from 0.57 to $0.93 .{ }^{14}$ In another study on the Chinese population, the overall Cronbach's $\alpha$ was 0.85 for the eight items and the item-total correlations were moderate or high $(r>0.5)$ for all the items, except for VT $(r=0.39) .{ }^{15}$

\section{Statistical analysis}

The results from the questionnaires were collected in an Excel spreadsheet and statistically analyzed. Variables were presented as mean (SD) and numbers (percentage). The normality of distribution was checked with the Shapiro-Wilk test, which revealed that none of the analyzed variables had a normal distribution. For the comparison of more than two groups, the Kruskal-Wallis test with the Duncan's test for post hoc comparisons was used. To determine predictive values of the variables that affect quality of life, linear regression analysis was carried out. The criteria for statistical significance were set at $P<0.05$. For the purpose of the statistical analysis, the R Package for Statistical Computing v. 3.4.4 was used.

\section{Results}

In this study, 185 patients were diagnosed with NSCLC. Only the groups of NSCLC were analyzed. The mean age of patients was $62.84 \pm 9.6$ with an age range between 58 and 68 years. Overall, $45.41 \%(\mathrm{n}=84)$ were women, $41.08 \%$ $(\mathrm{n}=76)$ lived alone, $56.76 \%(\mathrm{n}=105)$ had primary or vocational education, and $75.13 \%(\mathrm{n}=139)$ were malnourished or at risk of malnutrition. The characteristics of the study group are presented in Table 1.

The results of the quality of life assessment and of the evaluation of coping strategies are presented in Table 2. In the scope of quality of life, the study patients achieved higher scores in the BP, RE, and VT domains, whereas poor scores
Table I Characteristics of the study group of patients with nonsmall-cell lung carcinoma $(n=185)$

\begin{tabular}{|c|c|c|c|}
\hline \multicolumn{2}{|l|}{ Variables } & \multirow{2}{*}{$\begin{array}{l}n \\
4 I\end{array}$} & \multirow{2}{*}{$\begin{array}{l}\text { Percentage } \\
22.17\end{array}$} \\
\hline Classification of & TI & & \\
\hline malignant tumors & $\mathrm{T} 2$ & 76 & 41.09 \\
\hline \multirow[t]{4}{*}{$\mathrm{T}$} & T3 & 21 & 11.35 \\
\hline & $\mathrm{T} 4$ & 44 & 23.78 \\
\hline & $\mathrm{Tx}$ & 2 & 1.08 \\
\hline & Missing data & 1 & 0.54 \\
\hline \multirow{2}{*}{$\begin{array}{l}\text { Classification of } \\
\text { malignant tumors }\end{array}$} & No & 68 & 36.76 \\
\hline & NI & 42 & 22.70 \\
\hline \multirow[t]{3}{*}{$N$} & N2, N3 & 63 & 34.06 \\
\hline & $\mathrm{Nx}$ & 11 & 5.95 \\
\hline & Missing data & I & 0.54 \\
\hline \multirow{2}{*}{$\begin{array}{l}\text { Classification of } \\
\text { malignant tumors }\end{array}$} & Mo & 128 & 69.19 \\
\hline & MI & 38 & 20.54 \\
\hline \multirow[t]{2}{*}{$M$} & Mx & 18 & 9.73 \\
\hline & Missing data & I & 0.54 \\
\hline \multirow[t]{4}{*}{ TNM } & 1 & 68 & 36.76 \\
\hline & $\|$ & 42 & 22.70 \\
\hline & III & 18 & 9.73 \\
\hline & IV & 57 & 30.81 \\
\hline \multirow{6}{*}{$\begin{array}{l}\text { The presence of } \\
\text { comorbidities }\end{array}$} & Diabetes mellitus & 54 & 29.19 \\
\hline & Ischemic heart disease & 28 & 15.14 \\
\hline & Renal insufficiency & 6 & 3.24 \\
\hline & Rheumatoid arthritis & 4 & 2.16 \\
\hline & Heat failure & 36 & 19.46 \\
\hline & Asthma/COPD & 38 & 20.54 \\
\hline \multirow{5}{*}{$\begin{array}{l}\text { The presence of } \\
\text { metastases }\end{array}$} & Bone metastases & 10 & 5.41 \\
\hline & Brain metastases & 8 & 4.32 \\
\hline & Hepatic metastases & 17 & 9.19 \\
\hline & $\begin{array}{l}\text { Metastases to the } \\
\text { adrenal glands }\end{array}$ & 20 & 10.81 \\
\hline & Multi-organ metastases & 16 & 8.65 \\
\hline \multirow[t]{5}{*}{ Treatment } & Surgery & 132 & 71.35 \\
\hline & Radiotherapy & 55 & 29.73 \\
\hline & Chemotherapy & 102 & 55.14 \\
\hline & Symptomatic treatment & 16 & 8.65 \\
\hline & Alternative treatment & 3 & 1.62 \\
\hline \multirow{8}{*}{$\begin{array}{l}\text { The presence of } \\
\text { symptoms }\end{array}$} & Chronic cough & 149 & 80.54 \\
\hline & Dyspnea & 114 & 61.62 \\
\hline & Chest pain & 74 & 40.00 \\
\hline & Hemoptysis & 57 & 30.81 \\
\hline & Recurrent infections & 52 & 28.11 \\
\hline & $\begin{array}{l}\text { Superior vena cava } \\
\text { syndrome }\end{array}$ & 4 & 2.16 \\
\hline & Heart arrhythmia & 7 & 3.78 \\
\hline & Hoarseness & 52 & 28.11 \\
\hline Mini-nutritional & Malnourished & 95 & 51.35 \\
\hline \multirow[t]{2}{*}{ assessment } & At risk of malnutrition & 44 & 23.78 \\
\hline & $\begin{array}{l}\text { Normal nutritional } \\
\text { status }\end{array}$ & 46 & 24.86 \\
\hline WHO performance & Grade 0 & 34 & 18.38 \\
\hline \multirow[t]{4}{*}{ status } & Grade I & 80 & 43.24 \\
\hline & Grade 2 & 61 & 32.97 \\
\hline & Grade 3 & 9 & 4.86 \\
\hline & Grade 4 & 1 & 0.54 \\
\hline
\end{tabular}


Table 2 Characteristics of quality of life as measured using the SF-8 questionnaire and coping with the disease as measured using the MiniMAC scale

\begin{tabular}{|c|c|c|c|c|c|c|c|c|}
\hline Variables & $\mathbf{n}$ & Mean & SD & Median & Min & Max & Q I & Q3 \\
\hline \multicolumn{9}{|l|}{ Quality of life domains (SF-8) } \\
\hline $\mathrm{GH}$ & 185 & 28.65 & 22.2 & 25 & 0 & 75 & 0 & 50 \\
\hline VT & 185 & 52.16 & 36.43 & 50 & 0 & 100 & 50 & 100 \\
\hline $\mathrm{PF}$ & 185 & 31.89 & 36.25 & 0 & 0 & 100 & 0 & 50 \\
\hline $\mathrm{RP}$ & 185 & 42.7 & 49.6 & 0 & 0 & 100 & 0 & 100 \\
\hline SF & 185 & $45.4 I$ & 49.92 & 0 & 0 & 100 & 0 & 100 \\
\hline $\mathrm{MH}$ & 185 & 47.03 & 50.05 & 0 & 0 & 100 & 0 & 100 \\
\hline RE & 185 & 56.22 & 49.75 & 100 & 0 & 100 & 0 & 100 \\
\hline $\mathrm{BP}$ & 185 & 56.89 & 38.08 & 75 & 0 & 100 & 0 & 100 \\
\hline PCS & 185 & 40.07 & 28.58 & 37.5 & 0 & 93.75 & 18.75 & 68.75 \\
\hline MCS & 185 & 50.2 & 39.26 & 37.5 & 0 & 100 & 12.5 & 87.5 \\
\hline \multicolumn{9}{|c|}{ Strategies of coping with the disease (MiniMAC) } \\
\hline Anxious preoccupation & 185 & 19.64 & 4.86 & 20 & 7 & 28 & 16 & 23 \\
\hline Fighting spirit & 185 & 20.24 & 3.09 & 20 & 10 & 28 & 18 & 22 \\
\hline Helplessness-hopelessness & 185 & 14.92 & 3.58 & 15 & 7 & 25 & 13 & 17 \\
\hline Positive redefinition & 185 & 20.1 & 2.89 & 20 & 11 & 28 & 18 & 22 \\
\hline
\end{tabular}

Note: RE, role limitations due to emotional problems; RP, role limitations due to physical health problems.

Abbreviations: BP, bodily pain; GH, general health perceptions; max, maximum; MCS, mental component summary; MH, mental health; min, minimum; PCS, physical component summary; PF, physical functioning; SF, social functioning; SF-8, Short Form-8; VT, vitality.

in the PCS, PF, and GH domains. Mental functioning was better than PF. Regarding coping strategies, respondents most often employed the fighting strategy, whereas the sense of helplessness was employed least often. The styles of coping were assessed using standard ten norms (1-4 were classified as low; 5-6 as medium; and 7-10 as high). Overall, 65\% of the respondents displayed a medium level of constructive style, whereas $62 \%$ had a destructive style. The coping style of nearly $50 \%$ of the respondents was predominantly constructive. Characteristics of the coping style in the study groups are presented in Table 3.

A comparison of the quality of life scores between patients with different coping styles revealed that significant differences were found within every domain of quality of life. Overall, patients with a predominance of the constructive style had a significantly higher level of quality of life than patients with both a predominance of the destructive style and a balance between the two styles. The two exceptions were the domains of GH and MH. In the GH domain, the highest level of quality of life was observed among patients with a predominantly constructive style, a medium level of quality of life for patients with a balance between the two styles, and the lowest quality of life among those with a predominantly destructive style of coping. In the MH domain, the highest level of quality of life was observed among patients with a predominantly constructive style, whereas the remaining styles had a comparably lower quality of life. Table 4 shows the comparison of coping styles within the domains of quality of life.
Table 3 Styles of coping with the disease among lung cancer patients

\begin{tabular}{llll}
\hline Style & Level & $\mathbf{n}$ & Percentage \\
\hline Constructive & Low level & 26 & 14.05 \\
& Medium level & 120 & 64.86 \\
& High level & 39 & 21.08 \\
Destructive & Low level & 50 & 27.03 \\
& Medium level & 115 & 62.16 \\
& High level & 20 & 10.81 \\
Predominance of & - & 41 & 22.16 \\
destructive style & & & \\
Balance between styles & - & 56 & 30.27 \\
Predominance of & - & 88 & 47.57 \\
constructive style & & & \\
\hline
\end{tabular}

Other factors that were analyzed affected quality of life as well. A higher score in both PCS and MCS was inversely correlated with the number of symptoms $(r=-0.226 ; P=0.002$ and $r=-0.148 ; P=0.044)$. The highest PCS scores were found in patients with WHO grade 0 in comparison to other grades (the mean scores in WHO grades 0,1 , and 2-3 were 55.33, 45.47, and 26.58, respectively; $P<0.001$ ); in patients without comorbidities in comparison to those with comorbidities (the mean scores in patients without comorbidities, with 1, and with 2-3 comorbidities were 52.42, 36.66, and 28.05, respectively; $P<0.001$ ); in patients who were not subjected to a given type of treatment in comparison with those who were undergoing this type of treatment: radiotherapy (the mean scores for non-radiotherapy and radiotherapy groups were 43.7 and 31.36 , respectively; $P=0.007$ ), chemotherapy 
(the mean scores for non-chemotherapy and chemotherapy groups were 49.25 and 32.54 , respectively; $P<0.001$ ), and symptomatic treatment (the mean scores for non-symptomatic and symptomatic treatment groups were 41.38 and 25.78 , respectively; $P=0.046$ ). The highest MCS score was found in patients with WHO grade 0 in comparison to other grades (the mean scores in WHO grades 0,1 , and 2-3 were $61.76,55.31$, and 38.91, respectively; $P=0.004$ ); in patients without comorbidities in comparison to those with comorbidities (mean scores in patients without comorbidities, with 1, and with 2-3 comorbidities were 63.91, 47.56, and 34.76, respectively; $P<0.001$ ); in patients who were not subjected to surgery (the mean scores for non-surgery and surgery groups were 37.26 and 55.4, respectively; $P=0.002$ ), radiotherapy (the mean scores for non-radiotherapy and radiotherapy groups were 54.62 and 39.77 , respectively; $P=0.027$ ), chemotherapy (the mean scores for non-chemotherapy and chemotherapy groups were 65.06 and 38.11, respectively; $P<0.001$ ), and symptomatic treatment (the mean scores for non-symptomatic and symptomatic treatment groups were 52 and 31.25 , respectively; $P=0.025$ ). Patients with T1 had a higher MCS score than patients with T4 (the mean score was 61.89 vs 38.64 , respectively; $P=0.022$ ). Also, the better nourished the patients, the better quality of life they had $(P<0.001$ both for PCS and MCS). The comparison of coping styles within domains of quality of life is shown in Table 4.

Multivariate linear regression showed that after adjusting for other factors analyzed in the study, employing a constructive style of coping with the disease increases PCS by 12.83 points and MCS by 22.21 points on average. Among other significant positive predictors of quality of life were a lower WHO grade, symptomatic treatment, better nutritional status, and a higher level of education. The results of linear regression are presented in Table 5.

Table 4 Comparison of coping styles within domains of quality of life

\begin{tabular}{|c|c|c|c|c|c|c|c|}
\hline SF-8 & Predominance of coping style & $\mathbf{N}$ & Mean \pm SD & Median & Range & IQR & $\mathbf{P}$ \\
\hline \multirow[t]{3}{*}{$\mathrm{GH}$} & $\mathrm{D}$ & 41 & $14.63 \pm 15.79$ & 25 & $0-50$ & $0-25$ & $<0.001$ \\
\hline & B & 56 & $25 \pm 21.32$ & 25 & $0-75$ & $0-50$ & $\mathrm{C}>\mathrm{B}>\mathrm{D}$ \\
\hline & C & 88 & $37.5 \pm 21.44$ & 50 & $0-75$ & $25-50$ & \\
\hline \multirow[t]{3}{*}{ VT } & $\mathrm{D}$ & 41 & $31.71 \pm 31.14$ & 50 & $0-100$ & $0-50$ & $<0.001$ \\
\hline & B & 56 & $44.64 \pm 33.95$ & 50 & $0-100$ & $0-50$ & $C>B, D$ \\
\hline & C & 88 & $66.48 \pm 34.51$ & 50 & $0-100$ & $50-100$ & \\
\hline \multirow[t]{3}{*}{ PF } & $\mathrm{D}$ & $4 I$ & $|3.4| \pm 3 \mid .67$ & 0 & $0-100$ & $0-0$ & $<0.001$ \\
\hline & B & 56 & $24.11 \pm 30.14$ & 0 & $0-100$ & $0-50$ & $C>B, D$ \\
\hline & C & 88 & $45.45 \pm 36.86$ & 50 & $0-100$ & $0-50$ & \\
\hline \multirow[t]{3}{*}{ RP } & $\mathrm{D}$ & 41 & $19.5 \mathrm{I} \pm 40.12$ & 0 & $0-100$ & $0-0$ & $<0.001$ \\
\hline & B & 56 & $37.5 \pm 48.85$ & 0 & $0-100$ & $0-100$ & $C>B, D$ \\
\hline & C & 88 & $56.82 \pm 49.82$ & 100 & $0-100$ & $0-100$ & \\
\hline \multirow[t]{3}{*}{ SF } & $D$ & 41 & $26.83 \pm 44.86$ & 0 & $0-100$ & $0-100$ & 0.001 \\
\hline & B & 56 & $37.5 \pm 48.85$ & 0 & $0-100$ & $0-100$ & $C>B, D$ \\
\hline & $C$ & 88 & $59.09 \pm 49.45$ & 100 & $0-100$ & $0-100$ & \\
\hline \multirow[t]{3}{*}{$\mathrm{MH}$} & $\mathrm{D}$ & 41 & $26.83 \pm 44.86$ & 0 & $0-100$ & $0-100$ & 0.002 \\
\hline & B & 56 & $42.86 \pm 49.94$ & 0 & $0-100$ & $0-100$ & $C>D$ \\
\hline & $C$ & 88 & $59.09 \pm 49.45$ & 100 & $0-100$ & $0-100$ & \\
\hline \multirow[t]{3}{*}{ RE } & $D$ & 41 & $31.71 \pm 47.11$ & 0 & $0-100$ & $0-100$ & $<0.001$ \\
\hline & B & 56 & $51.79 \pm 50.42$ & 100 & $0-100$ & $0-100$ & $C>B, D$ \\
\hline & $C$ & 88 & $70.45 \pm 45.89$ & 100 & $0-100$ & $0-100$ & \\
\hline \multirow[t]{3}{*}{ BP } & $\mathrm{D}$ & 41 & $43.29 \pm 39.54$ & 50 & $0-100$ & $0-75$ & $<0.001$ \\
\hline & B & 56 & $46.88 \pm 37.86$ & 50 & $0-100$ & $0-75$ & $C>B, D$ \\
\hline & C & 88 & $69.6 \pm 33.57$ & 75 & $0-100$ & $50-100$ & \\
\hline \multirow[t]{3}{*}{ PCS } & $D$ & 41 & $22.7 I \pm 22.52$ & 18.75 & $0-87.5$ & $0-25$ & $<0.001$ \\
\hline & B & 56 & $33.37 \pm 24.95$ & 31.25 & $0-93.75$ & $12.5-56.25$ & $C>B, D$ \\
\hline & C & 88 & $52.4 I \pm 27.85$ & 56.25 & $0-93.75$ & 29.69-75 & \\
\hline \multirow[t]{3}{*}{ MCS } & $D$ & 41 & $29.27 \pm 34.64$ & 12.5 & $0-100$ & $0-62.5$ & $<0.001$ \\
\hline & B & 56 & $44.23 \pm 8.36$ & 37.5 & $0-100$ & $12.5-87.5$ & $C>B, D$ \\
\hline & $C$ & 88 & $63.78 \pm 36.9$ & 75 & $0-100$ & $34.38-100$ & \\
\hline
\end{tabular}

Notes: B, balance between constructive and destructive style of coping with the disease; C, predominance of constructive style; D, predominance of destructive style; RE, role limitations due to emotional problems; RP, role limitations due to physical health problems.

Abbreviations: BP, bodily pain; GH, general health perceptions; IQR, interquartile range; $\mathrm{MH}$, mental health; MCS, mental component summary; PCS, physical component summary; PF, physical functioning; SF, social functioning; SF-8, Short Form-8; VT, vitality. 
Table 5 Results of multivariate linear regression

\begin{tabular}{|c|c|c|c|c|c|c|c|}
\hline & & \multicolumn{3}{|c|}{ Physical component summary } & \multicolumn{3}{|c|}{ Mental component summary } \\
\hline & & $\begin{array}{l}\text { Regression } \\
\text { coefficient }\end{array}$ & $95 \% \mathrm{Cl}$ & $\mathbf{P}$ & $\begin{array}{l}\text { Regression } \\
\text { coefficient }\end{array}$ & $95 \% \mathrm{Cl}$ & $P$ \\
\hline FEVI & & 1.234 & $-4.56-7.03$ & 0.674 & 1.842 & $-7.79-11.48$ & 0.706 \\
\hline FVC & & -2.143 & $-6.75-2.46$ & 0.359 & -2.611 & $-10.27-5.048$ & 0.501 \\
\hline FEVI/FVC [\%] & & -0.013 & $-0.25-0.22$ & 0.913 & 0.189 & $-0.2-0.58$ & 0.342 \\
\hline Number of symptoms & & 0.179 & $-2.09-2.45$ & 0.876 & 1.7 & $-2.07-5.47$ & 0.374 \\
\hline \multirow[t]{2}{*}{ Sex } & Women & Reference & & & Reference & & \\
\hline & Men & 0.275 & $-5.77-6.32$ & 0.929 & 2.787 & $-7.27-12.85$ & 0.585 \\
\hline \multirow[t]{2}{*}{ Age } & $\leq 60$ years & Reference & & & Reference & & \\
\hline & $>60$ years & -2.125 & $-8.4 \mid-4.16$ & 0.505 & -0.887 & $-11.35-9.57$ & 0.867 \\
\hline \multirow[t]{2}{*}{ Marital status } & In relationship & Reference & & & Reference & & \\
\hline & Alone & 1.538 & $-4.86-7.94$ & 0.636 & 6.737 & $-3.91-17.38$ & 0.213 \\
\hline \multirow[t]{5}{*}{ Education } & Primary & Reference & & & Reference & & \\
\hline & Vocational & -0.178 & $-10.9-10.5$ & 0.974 & -8.6 & $-26.37-9.17$ & 0.34 \\
\hline & Secondary & -1.293 & $-|2.8-10.2|$ & 0.824 & -17.609 & $-36.73-1.52$ & 0.071 \\
\hline & Higher & -6.684 & $-21.01-7.64$ & 0.358 & -33.714 & -57.54 to & 0.006 \\
\hline & & & & & & -9.89 & \\
\hline \multirow[t]{4}{*}{ WHO grade } & 0 & Reference & & & Reference & & \\
\hline & 1 & -7.687 & $-15.72-0.347$ & 0.061 & -6.988 & $-20.35-6.37$ & 0.303 \\
\hline & $2-4$ & -16.814 & -25.60 to & $<0.001$ & -10.206 & $-24.82-4.41$ & 0.17 \\
\hline & & & -8.03 & & & & \\
\hline Classification of & TI & Reference & & & Reference & & \\
\hline \multirow[t]{3}{*}{ malignant tumors $-T$} & $\mathrm{~T} 2$ & -0.909 & $-8.36-6.55$ & 0.81 & -3.281 & $-15.68-9.12$ & 0.602 \\
\hline & T3 & 0.127 & $-11.04-11.29$ & 0.982 & -9.576 & $-28.15-8.99$ & 0.31 \\
\hline & $\mathrm{T} 4$ & 6.869 & $-3.54-17.28$ & 0.194 & -7.762 & $-25.08-9.55$ & 0.377 \\
\hline Classification of & No & Reference & & & Reference & & \\
\hline \multirow[t]{3}{*}{ malignant tumors $-\mathrm{N}$} & NI & -2.508 & $-10.46-5.47$ & 0.535 & -4.723 & $-17.99-8.54$ & 0.483 \\
\hline & N2-3 & -0.924 & $-8.82-6.97$ & 0.817 & 6.848 & $-6.28-19.97$ & 0.304 \\
\hline & $\mathrm{Nx}$ & -10.285 & $-24.66-4.09$ & 0.159 & -10.9 & $-34.8-13.01$ & 0.369 \\
\hline Classification of & Mo & Reference & & & Reference & & \\
\hline \multirow[t]{2}{*}{ malignant tumors $-M$} & MI & 1.968 & $-6.37-10.30$ & 0.641 & 9.699 & $-4.16-23.56$ & 0.169 \\
\hline & $M x$ & -7.127 & $-17.65-3.4$ & 0.183 & -4.558 & $-22.07-12.95$ & 0.608 \\
\hline \multirow[t]{3}{*}{ Comorbidities } & None & Reference & & & Reference & & \\
\hline & 1 & -6.389 & $-13.47-0.69$ & 0.077 & 0.671 & $-11.11-12.45$ & 0.91 \\
\hline & $2-3$ & -4.435 & $-13.34-4.46$ & 0.326 & -2.387 & $-|7.19-| 2.4 \mid$ & 0.75 \\
\hline \multirow[t]{2}{*}{ Metastases } & No & Reference & & & Reference & & \\
\hline & Yes & -3.39 & $-10.96-4.18$ & 0.378 & -7.537 & $-20.13-5.05$ & 0.239 \\
\hline \multirow[t]{2}{*}{ Surgery } & No & Reference & & & Reference & - & \\
\hline & Yes & -0.301 & $-9.7 I-9.11$ & 0.95 & 6.015 & $-9.63-21.66$ & 0.449 \\
\hline \multirow[t]{2}{*}{ Radiotherapy } & No & Reference & & & Reference & & \\
\hline & Yes & 0.485 & $-6.88-7.85$ & 0.897 & -1.017 & $-13.26-11.23$ & 0.87 \\
\hline \multirow[t]{2}{*}{ Chemotherapy } & No & Reference & & & Reference & & \\
\hline & Yes & -2.953 & $-11.02-5.12$ & 0.471 & -4.685 & $-18.1-8.73$ & 0.491 \\
\hline \multirow[t]{2}{*}{ Symptomatic treatment } & No & Reference & & & Reference & & \\
\hline & Yes & 11.918 & $0.82-23.01$ & 0.035 & 12.984 & $-5.47-31.43$ & 0.166 \\
\hline \multirow[t]{3}{*}{ MNA } & Malnourished & Reference & & & Reference & & \\
\hline & $\begin{array}{l}\text { At risk of } \\
\text { malnutrition }\end{array}$ & 7.303 & $-0.34-14.95$ & 0.061 & 12.869 & $0.15-25.59$ & 0.047 \\
\hline & Normal & 28.038 & $20.19-35.88$ & $<0.001$ & 32.458 & $|9.4|-45.5 \mid$ & $<0.001$ \\
\hline \multirow[t]{3}{*}{ Coping style } & $\mathrm{D}$ & Reference & & & Reference & & \\
\hline & B & 1.957 & $-5.94-9.85$ & 0.625 & 5.881 & $-7.24-19.01$ & 0.377 \\
\hline & C & 12.826 & $4.99-20.66$ & 0.002 & 22.211 & $9.18-35.25$ & 0.001 \\
\hline
\end{tabular}

Note: B, balance between constructive and destructive style of coping with the disease; C, predominance of constructive style; D, predominance of destructive style. Abbreviation: MNA, Mini-Nutritional Assessment. 


\section{Discussion}

The results of this study provide important insights into coping strategies employed by patients with lung cancer. In this study group, a fighting strategy was most frequently observed, whereas a sense of helplessness was employed least often. Patients with a predominance of the constructive style of coping had a significantly higher level of quality of life. Regarding quality of life, the patients in the study achieved higher scores in the domains of BP, RE, and VT, whereas poor scores in the domains of PCS, PF, and GH. Patients achieved higher score in MCS than in PCS. Apart from the type of coping strategy, quality of life was associated with the patients' general state of health and the progression of the disease, which translated into a negative correlation between quality of life and the number of symptoms and comorbidities, the WHO grade, malnutrition, and being subjected to treatments such as surgery, radiotherapy, chemotherapy, and symptomatic treatment. The limitations of this study include the potential bias arising from the use of self-reported questionnaires; however, this is the nature of short form questionnaires. There was no control group in this study and as a result, we were able to identify a correlation between quality of life and coping with the disease only among lung cancer patients.

The relationship between quality of life and coping strategy is complex and additionally may be affected by many other factors. Studies from the literature suggest a reduced quality of life in patients with lung cancer. Lee et a ${ }^{16}$ reported that quality of life in NSCLC patients was lower in comparison to healthy controls, especially when measured up to 1 year after diagnosis. A comparison of health-related quality of life among cancer survivors performed by So et $\mathrm{al}^{17}$ suggested that lung cancer patients may experience a lower level of quality of life than patients with other types of cancers, especially in the area of functional well-being. Liao et $\mathrm{al}^{18}$ examined a group of patients with newly diagnosed stage IIIB or stage IV lung cancer and revealed that they had a compromised global quality of life and relatively low social and role functioning at 3 months after the diagnosis of cancer. Wang and $\mathrm{Fu}^{19}$ evaluated quality of life in Chinese patients with lung cancer and found that quality of life scores were lowest on the functioning subscale, whereas they were highest on the family subscale. The most frequent severe symptoms reported by those patients were fatigue, dry mouth, and shortness of breath. Those findings are in line with the results of this study, as quality of life in patients from this study group had low scores in the domains of GH and PCS, which are the most likely to be affected by the severity of pulmonary symptoms. It is worth noting that a cross-sectional survey completed by 660 lung cancer patients showed that quality of life was ranked the first and most important factor out of other factors experienced by those patients. ${ }^{20}$

Only a few studies have addressed coping strategies in patients with neoplastic diseases, despite the fact that coping is considered one of the key components of health and overall quality of life as the coping strategy used by patients affects their emotions and motivation during the stressful period of the illness. Tuncay ${ }^{21}$ examined the influence of coping on quality of life among 228 patients with ovarian cancer. He found that more patients employed problem-focused coping strategies, such as acceptance, emotional support, and religion, than emotion-focused coping strategies, such as self-distraction, venting, and behavioral disengagement. Additionally, more problem-focused and less emotion-focused coping predicted a higher level of quality of life. Kershaw et $\mathrm{a}^{22}$ found that active coping was correlated with higher level of quality of life, whereas avoidant coping was correlated with a lower level of quality of life in patients with advanced breast cancer. Horney et $\mathrm{al}^{23}$ revealed the occurrence of the association between negative coping styles and a high anxiety level as well as between a low level of optimism and a higher level of depression in 103 patients just after being given a diagnosis of head and neck cancer. Our findings are similar and show that a constructive style of coping is associated with a higher quality of life.

Regarding lung cancer, we found only a few studies addressing coping strategies. Mosher et $\mathrm{al}^{24}$ focused on identifying strategies of coping with physical and psychological symptoms of advanced lung cancer although they did not study their influence on quality of life. They found that in a group of 38 patients, religious and cognitive coping strategies such as changing expectations, maintaining positivity, and avoiding illnessrelated thoughts were the most frequently reported. A group of 243 patients with lung cancer undergoing chemotherapy in outpatient settings from a study by Czerw et $\mathrm{al}^{25}$ predominantly employed the fighting spirit strategy of coping. Rolke et $\mathrm{al}^{26}$ reported significantly reduced coping abilities as measured by the Sense of Coherence questionnaire in depressed patients with primary lung cancer in comparison to nondepressed ones, but no association was found between the ability to cope and the total score for quality of life. Interestingly, a significant association appeared between coping abilities and the emotional functioning domain of quality of life. In the study performed by Liao et al, ${ }^{18}$ self-efficacy for coping with cancer was the most important predictive factor for quality of life in patients with newly diagnosed advanced lung cancer.

This study brings new insights into the status of coping strategies among lung cancer patients. We found that the 
majority of patients employed positive fighting strategies for coping, which is in line with the previously published papers. We also found a strong association between the type of coping and the level of quality of life, despite the fact that quality of life is a complex condition and it is influenced by many other factors. This study highlights the need to evaluate types of coping strategies and quality of life in patients with lung cancer. Patient-oriented outcomes are important for treatment and prognosis; although, they are rarely screened in clinical practice. This type of support requires further research. We believe that this study will help physicians to support patients in using the most effective coping strategies.

\section{Conclusion}

The majority of patients with lung cancer use effective strategies for coping with the disease based on the constructive style. Patients who used a predominantly constructive style had a significantly higher level of quality of life, which may translate into better outcomes. Physicians should support patients in coping with lung cancer and provide interventions that promote positive, constructive, problem-oriented strategies, especially in patients with a lower level of quality of life, a more advanced disease, and comorbidities.

\section{Acknowledgment}

This study was performed within project number ST.E020.17.050 of Wroclaw Medical University.

\section{Disclosure}

The authors report no conflicts of interest in this work.

\section{References}

1. Steed LG. A Critique of Coping Scales. Aust Psychol. 1998;33(3):193-202.

2. Kato T. Frequently Used Coping Scales: A Meta-Analysis. Stress Health. 2015;31(4):315-323.

3. Dunkel-Schetter C, Feinstein LG, Taylor SE, Falke RL. Patterns of coping with cancer. Health Psychol. 1992;11(2):79-87.

4. Watson M, Greer S, Young J, Inayat Q, Burgess C, Robertson B. Development of a questionnaire measure of adjustment to cancer: the MAC scale. Psychol Med. 1988;18(1):203-209.

5. Diehl M, Chui H, Hay EL, Lumley MA, Grühn D, Labouvie-Vief G. Change in coping and defense mechanisms across adulthood: longitudinal findings in a European American sample. Dev Psychol. 2014;50(2):634-648.

6. Chabowski M, Polański J, Mazur G, Janczak D, Rosińczuk J. Sociodemographic and Clinical Determinants of Quality of Life of Patients with Non-small Cell Lung Cancer. Adv Exp Med Biol. 2017;1022:1-10.
7. Arraras JI, Hernandez B, Martinez M, et al. Quality of Life in Spanish advanced non-small-cell lung cancer patients: determinants of global QL and survival analyses. Springerplus. 2016;5(1):836.

8. de Oliveira PI, Pereira CA, Belasco AG, Bettencourt AR. Comparison of the quality of life among persons with lung cancer, before and after the chemotherapy treatment. Rev Lat Am Enfermagem. 2013;21(3):787-794.

9. Hanna E, Rémuzat C, Auquier P, Toumi M. Advanced therapy medicinal products: current and future perspectives. J MarkAccess Health Policy. 2016;4:31036.

10. Watson M, Law M, Santos M, Greer S, Baruch J, Bliss J. The MiniMAC: Further development of the Mental Adjustment to Cancer Scale. Journal of Psychosocial Oncology. 1994;12:33-45.

11. Juczyński Z. Narzędzia pomiaru w promocji i psychoonkologii zdrowia. Warszawa: Pracownia Testów Psychologicznych; 2009.

12. Czerw AI, Marek E, Deptała A. Use of the mini-MAC scale in the evaluation of mental adjustment to cancer. Contemp Oncol (Pozn). 2015;19(5): 414-419.

13. Ware J, Kosinski M, Dewey J, Gandek B. How to Score and Interpret Single-Item Health Status Measures: A Manual for Users of the SF-8 Health Survey. Boston: QualyMetric; 2001.

14. Valencia L, Valles J, Williams M, Briones Z, Guilera M. Validity and clinical applicability of SF-8 quality of life questionnaire in surgical patients: A population-based study 1AP4-6. EUROANAESTHESIA 2008: Evidence-Based Practice and Quality Assurance. European Journal of Anaesthesiology. 2008;25:16-17.

15. Lang L, Zhang L, Zhang P, Li Q, Bian J, Guo Y. Evaluating the reliability and validity of SF-8 with a large representative sample of urban Chinese. Health Qual Life Outcomes. 2018;16(1):55.

16. Lee LJ, Chung CW, Chang YY, et al. Comparison of the quality of life between patients with non-small-cell lung cancer and healthy controls. Qual Life Res. 2011;20(3):415-423.

17. So WK, Ling GC, Choi KC, et al. Comparison of health-related quality of life and emotional distress among Chinese cancer survivors. Int $J$ Nurs Pract. 2013;19(3):306-317.

18. Liao YC, Shun SC, Liao WY, Yu CJ, Yang PC, Lai YH. Quality of life and related factors in patients with newly diagnosed advanced lung cancer: a longitudinal study. Oncol Nurs Forum. 2014;41(2):E44-E55.

19. Wang D, Fu J. Symptom clusters and quality of life in China patients with lung cancer undergoing chemotherapy. Afr Health Sci. 2014;14(1): $49-55$.

20. Gralla RJ, Hollen PJ, Msaouel P, Davis BV, Petersen J. An evidencebased determination of issues affecting quality of life and patientreported outcomes in lung cancer: results of a survey of 660 patients. J Thorac Oncol. 2014;9(9):1243-1248.

21. Tuncay T. Coping and quality of life in Turkish women living with ovarian cancer. Asian Pac J Cancer Prev. 2014;15(9):4005-4012.

22. Kershaw T, Northouse L, Kritpracha C, Schafenacker A, Mood D. Coping strategies and quality of life in women with advanced breast cancer and their family caregivers. Psychol Health. 2004;19(2):139-155.

23. Horney DJ, Smith HE, McGurk M, et al. Associations between quality of life, coping styles, optimism, and anxiety and depression in pretreatment patients with head and neck cancer. Head Neck. 2011;33(1):65-71.

24. Mosher CE, Ott MA, Hanna N, Jalal SI, Champion VL. Coping with physical and psychological symptoms: a qualitative study of advanced lung cancer patients and their family caregivers. Support Care Cancer. 2015;23(7):2053-2060.

25. Czerw AI, Religioni U, Deptała A. Adjustment to Life with Lung Cancer. Adv Clin Exp Med. 2016;25(4):733-740.

26. Rolke HB, Bakke PS, Gallefoss F. Health related quality of life, mood disorders and coping abilities in an unselected sample of patients with primary lung cancer. Respir Med. 2008;102(10):1460-1467. 
Cancer Management and Research

\section{Publish your work in this journal}

Cancer Management and Research is an international, peer-reviewed open access journal focusing on cancer research and the optimal use of preventative and integrated treatment interventions to achieve improved outcomes, enhanced survival and quality of life for the cancer patient.

The manuscript management system is completely online and includes

Submit your manuscript here: https://www.dovepress.com/cancer-management-and-research-journal

a very quick and fair peer-review system, which is all easy to use. Visit $\mathrm{http}: / / \mathrm{www}$.dovepress.com/testimonials.php to read real quotes from published authors. 